\title{
The Effect of Tool Rotation Speed on Mechanical Properties of Friction Stir Spot Welded (FSSW) AA7075-T6 Aluminium Alloy Sheets
}

\author{
Mustafa Uğurlu*, Ahmet Çakan \\ Mersin University, Faculty of Engineering, Department of Mechanical Engineering, Mersin, Turkey \\ ORCID: M. Uğurlu (0000-0002-1194-7772), A. Çakan (0000-0002-7394-1499)
}

\begin{abstract}
In this study, the effect of tool rotation speed on the mechanical and metallurgical properties of friction stir spot welded (FSSW) AA7075-T6 aluminum alloy sheets was investigated. Aluminum alloy plates were joined by FSSW using welding parameters consisting of three different rotation speeds of 1040, 1320 and $1500 \mathrm{rpm}$ and a constant insertion depth of $3.2 \mathrm{~mm}$. In spot welded specimens, the highest tensile strength value $(6200 \mathrm{~N})$ was obtained in plates welded at a tool rotation speed of $1500 \mathrm{rpm}$. The data obtained from the metallographic analysis are compatible with the tensile test results. Metallographic investigations demonstrated that there was a small amount of porosity in the welding zone of the specimens jointed at $1500 \mathrm{rpm}$.
\end{abstract}

Keywords: Solid state welding, Friction stir spot welding, Mechanical properties, AA 7075-T6.

\section{INTRODUCTION}

Producing automobile bodies from lightweight materials is known to provide fuel economy and to reduce carbon emission values [1]. Due to its superior properties such as low density and strength, aluminum quickly takes the place of steel plates in the automotive industry [2]. The joining of steel sheets is accomplished by joining methods such as rivets, bolts, and spot welding. Joining with spot welding comes to the fore since it does not form extra weight and additional costs. The most common technique used as spot welding in the industry is electrical resistance spot welding. Joining sheet metals by electrical resistance spot welding is advantageous due to its properties such as welding efficiency and compatibility with automation [3]. The presence of an oxide layer in the welded joining of aluminum plates and causing a high rate of electrode wear make the use of electrical resistance spot welding difficult [2]. Furthermore, in joining aluminum sheets, resistance spot welding produces a weak weld seam and causes porosity formation $[4,5]$. The electrical resistance spot welding technique remains incapable of the welded joining of aluminum-based sheets due to the loss of the alloy property with the evaporation of the alloying element, shorter electrode life, hydrogen fracture, wear, overheating, and melting [6].
Friction stir welding (FSW) developed by the Welding Institute (TWI) in 1991 is a process involving thermodynamic processes during which instant heat formation, cooling, flow and deformation, recrystallization and mechanical coupling occur. FSW is a relatively new method, which is used in welding of metals without melting, with its properties such as low distortion, good mechanical properties, little weld defects, superior welding properties provided in some metals that cannot be welded by conventional welding methods [711].

In 2003, the method of spot welding was developed by Mazda Motor Company on the basis of friction spot welding (FSW), which is one of the solid-state welding methods $[12,13]$. With this method called friction stir spot welding (FSSW), parts are welded without fusion. Therefore, welding defects such as porosity and cracks in the weld seam can be minimized $[14,15]$. The FSSW technique, which presents high mechanical properties and which forms low distortion and low residual stress due to the low temperature difference in the welding process, also offers advantages such as the ease of use, high corrosion resistance, low energy input, and low cost $[3,17]$. With these properties, the FSSW technique is taking the place of resistance spot welding in the automotive industry [17]. 
In FSS welding of metal-based sheets, tool design is essential. In the FSSW method, a nonconsumable tool with a pin and a shoulder on it is inserted gradually onto the overlapping sheets by rotating at high speed $[3,18]$. The tool rotates for a certain period without feeding movement. This phase is defined as the dwelling time. The heat generated between the tool and the workpiece due to friction softens the workpiece, and the joining process is accomplished by stirring with the rotational movement. The rotating tool is removed from the workpiece by the upward movement, and the welding process is completed $[3,7,19]$.

The effect of tool rotational speed, which is one of the important welding parameters, has been studied in the literature. In these studies, the rotational speed has different effects on welding performance. Cao et al. [20] reported that tensile strength initially increases with increasing tool rotational speed but decreases with further increase. Zhang et al. [21] said that the results of tensile tests indicate the joint performance decreases with increasing rotational speed. Gerlich et al. [22] said that the material transport is insufficient when the tool rotation speed is selected as $750 \mathrm{rpm}$. Furthermore, Babu et al. [18] reported that bond width increased up to $1500 \mathrm{rpm}$ and decreased at higher tool rotational speeds due to excessive heating.

In this study, the tensile test and microhardness tests were performed to determine the effect of tool rotation speed, which is one of the most critical parameters affecting the welding performance in joining AA 7075-T6 Aluminum alloy sheets by FSSW, on the mechanical properties of welding. Metallographic examination of the welding zone was performed with an optical microscope.

\section{MATERIAL AND METHOD}

In this study, AA7075-T6 aluminum alloy plates 100x30x3 $\mathrm{mm}$ in size were used. AA7075-T6 sheets were spot welded by using the FSSW method (Figure 1). The chemical composition of AA7075-T6 aluminum material is presented in Table 1.

H13 hot work tool steel, which is widely used in hot and cold forming processes and which has superior properties such as high wear resistance, toughness, availability to machining, was used as a tool in the FSS-welding process. The tool consists of a pin, shoulder, and body carrying them. The tool with a shoulder diameter of $20 \mathrm{~mm}$, a pin diameter of $8 \mathrm{~mm}$ and a pin length of $3 \mathrm{~mm}$ was manufactured by using the machining method, and the end zone (pin, shoulder) was hardened by heat treatment. The tool which was designed and manufactured for the realization of experimental studies is presented in Figure 2.

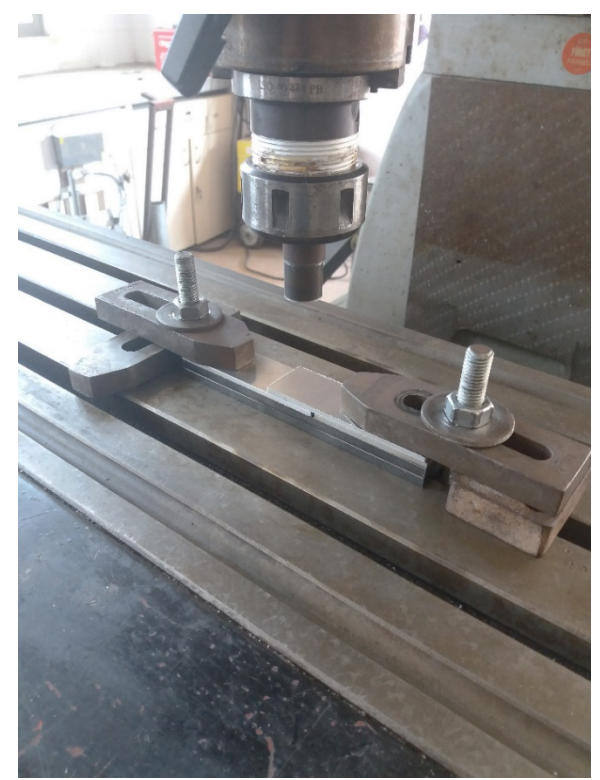

Figu. 1. Friction Stir Spot Welding system

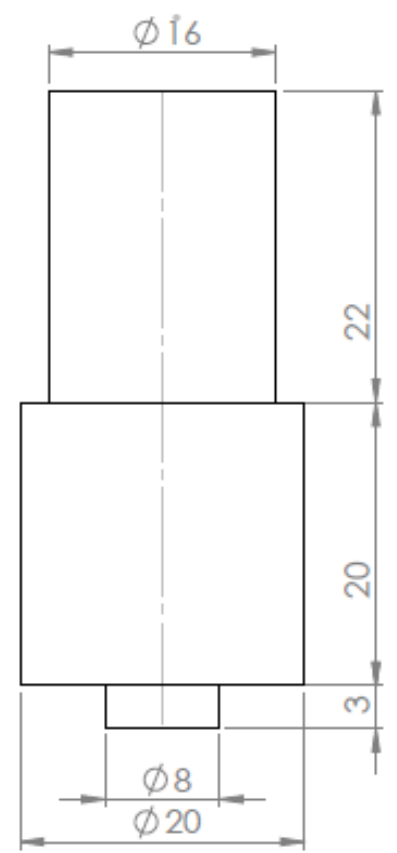

Fig. 2. Tool used in the FSSW process

FSS-welding of aluminum alloy plates was performed by using a $2.8 \mathrm{~kW}$ FIRST LC20VGN universal milling machine with the vertical head at three different speeds (1040, 1320, and $1500 \mathrm{rpm}$ ) with a $20 \mathrm{~s}$ dwelling time, under room conditions, on a $30 \mathrm{~mm}$ x $30 \mathrm{~mm}$ overlap area.

It was ensured that the tool rotated clockwise by setting the milling machine to the specified cycle parameters. After completing these preparations, the FSSW process, of which schematic representation is shown in Figure 3 and which consists of plunging, stirring, and retraction stages, was started.

Table 1. The chemical composition of AA7075-T6 aluminum alloy plates

\begin{tabular}{|c|c|c|c|c|c|c|c|c|c|c|c|c|c|}
\hline \multirow[t]{2}{*}{ Material } & \multicolumn{13}{|c|}{ Chemical Composition (\% weight) } \\
\hline & $\mathrm{Si}$ & $\mathrm{Fe}$ & $\mathrm{Cu}$ & $M n$ & $M g$ & $\mathrm{Cr}$ & $\mathrm{Ni}$ & $\mathrm{O}$ & $\mathrm{Zn}$ & $\mathrm{Ti}$ & $\mathrm{Zr}$ & $\mathrm{Al}$ & $\mathrm{Pb}$ \\
\hline AA7075-T6 & 0.07 & 0.14 & 1.6 & 0.06 & 2.7 & 0.19 & $60 \mathrm{ppm}$ & - & 5.8 & 0.02 & 0.01 & 89.41 & - \\
\hline
\end{tabular}


In the first stage, the tool's tip rotating at a specified speed penetrated the part with the plunge rate of $0.2 \mathrm{~mm} / \mathrm{s}$ of the milling table in the perpendicular direction. The upward movement of the table was continued until the shoulder contacted the parts. After providing the contact of the shoulder of the rotating tool, of which pin was inserted into the workpiece, with the base metal, the plunge amount was adjusted, and it waited for $20 \mathrm{~s}$. The surface views of welded joints produced at different welding parameters are presented in Figure 4.
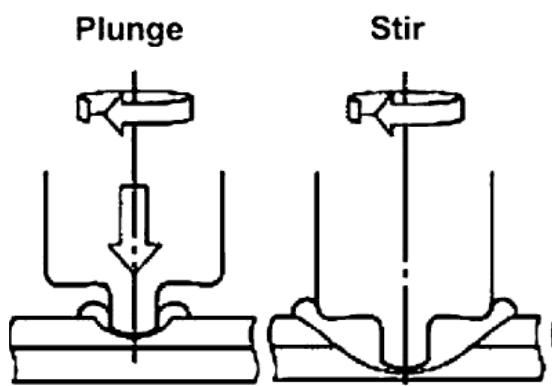

Withdraw

Fig. 3. Schematic representation of the FSSW process [18].

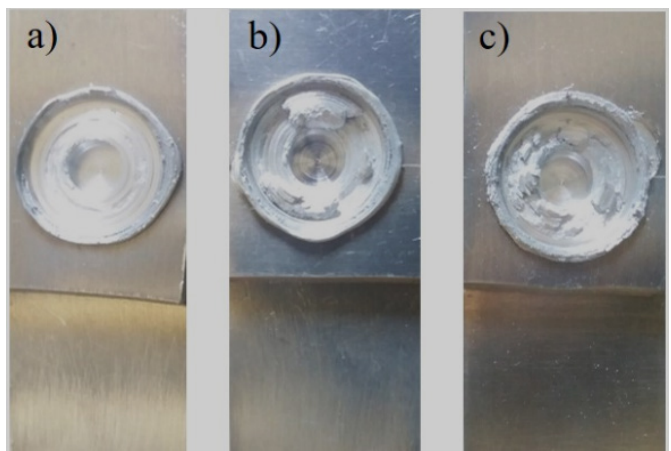

Fig. 4. Top (surface) views of FSS-welded joints at different welding parameters a) $1040 \mathrm{rpm}$, b) $1320 \mathrm{rpm}$, and c) $1500 \mathrm{rpm}$.

In the determination of the mechanical properties of the specimens FSS welded by using three different speed parameters (1040, 1320, $1500 \mathrm{rpm})$, the universal tensile test device (Raagen) with $10 \mathrm{kN}$ load capacity was used. The tensile test was applied to the specimens at a loading speed of 1 $\mathrm{mm} / \mathrm{min}$ under room conditions.

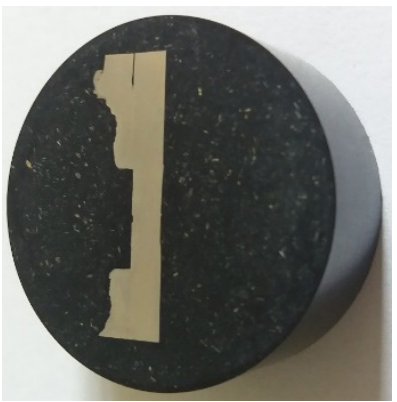

Fig. 5. Specimen prepared for the microstructural examination
ZEISS Stereo Discovery.V8 optical microscope was used in the metallographic analysis of the welded parts obtained by using three different rotation speeds (1040, 1320, 1500 $\mathrm{rpm}$ ). For the metallographic analysis, the specimen (Figure 5) was exposed to etching after sanding and polishing. Vickers hardness values of the welded parts were determined by applying $0.98(\mathrm{~N})$ load for $15 \mathrm{~s}$ to the specimens.

\section{RESULTS AND DISCUSSION}

\subsection{Metallographic Characterization of the Weld}

The optical micrograph of the FSS welded joints produced using three different rotation speeds of the tool are presented in Figure 6. The optical microscope views of welded joints produced at all applied parameters, it is observed that good weld penetration was achieved with a gapless joint. In the welding zone of FSS-welded aluminum plates produced at the low rotation speeds of the tool, interface of the joint is partially apparent, and the presence of a small amount of porosity is observed (Figure 6a, b). In the welding zone of FSS-welded aluminum plates produced at the high tool rotation speed (1500 rpm), the interface line was not apparent, and the presence of porosity was not observed (Figure 6c). The stir zone was found to be larger with increasing tool rotation speed. Bozzi et al. [23] obtained similar results and explained the increase in the stir zone with more heat generation.

\subsection{Examination of Tensile-Shear Forces}

Tensile loads of FSS welded joints were determined by applying tensile tests. The fracture surface on the lower sheets and the top views of the welding surface on the upper sheets are presented in Figure 7. Similar to the pin on the tool, the presence of a pit on the upper sheet, and along with the trail formed by the heat effect due to the pressure friction of the shoulder, the presence of the material transferred from the upper plate around the region where the pin contacted was observed on the lower plate. The FSS-welded plates joined at three different rotation speeds have similarities in the welding zone.

Tensile-shear forces and elongation relationship of the welded parts obtained using different rotation speeds is presented in Figure 8. An increase in the tensile force depending on the increasing tool rotation speed is observed (Figure 8). The highest tensile-shear load value $(6200 \mathrm{~N})$ is obtained at the tool rotation speed of $1500 \mathrm{rpm}$. Paidar et al. [24] determined that the tensile strength increases with increasing tool rotational speed. Patel et al. [25] have also determined that the tensile strength increased with the increase of tool
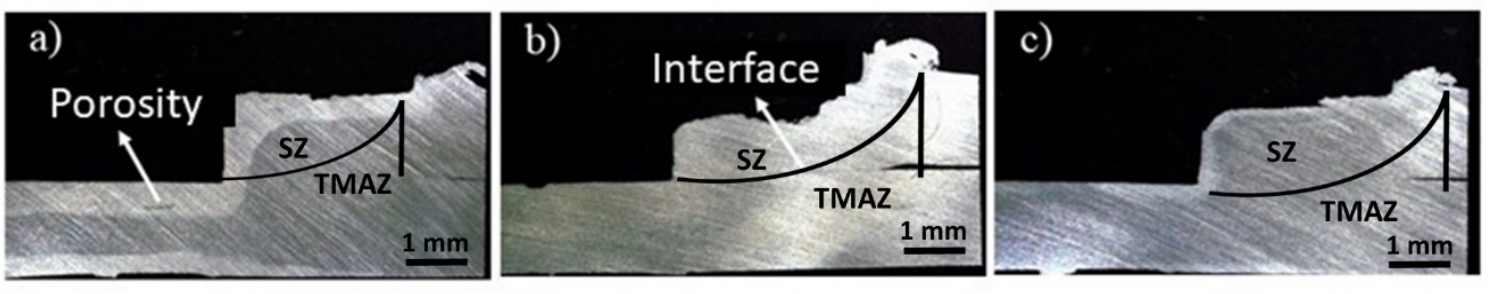

Fig. 6. The Optical micrographs of welded joints obtained using different rotation speeds, a) $1040 \mathrm{rpm}$, b) $1320 \mathrm{rpm}$, and c) $1500 \mathrm{rpm}$ 
rotation speed and obtained the highest strength value at $1500 \mathrm{rpm}$. Bozzi et al. [23] explained the increase in the tensile strength with increasing tool rotation speed, because of the larger size of the stir zone.

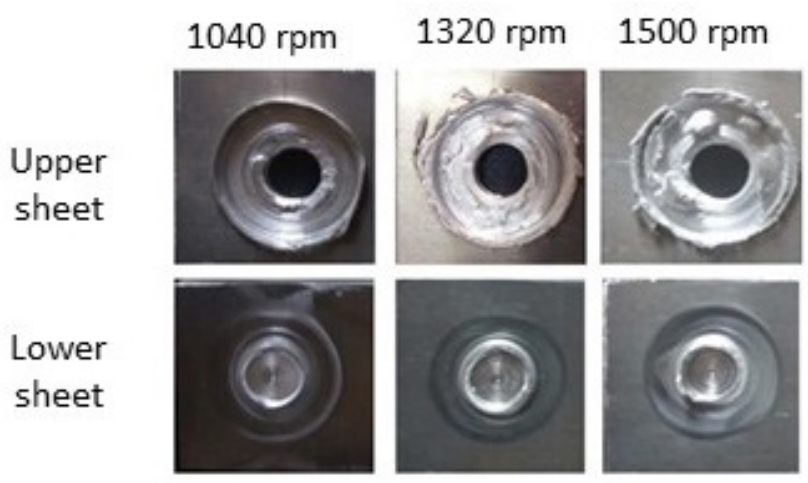

Fig. 7. Enlarged images of welding zones on the top and bottom plates after the tensile test

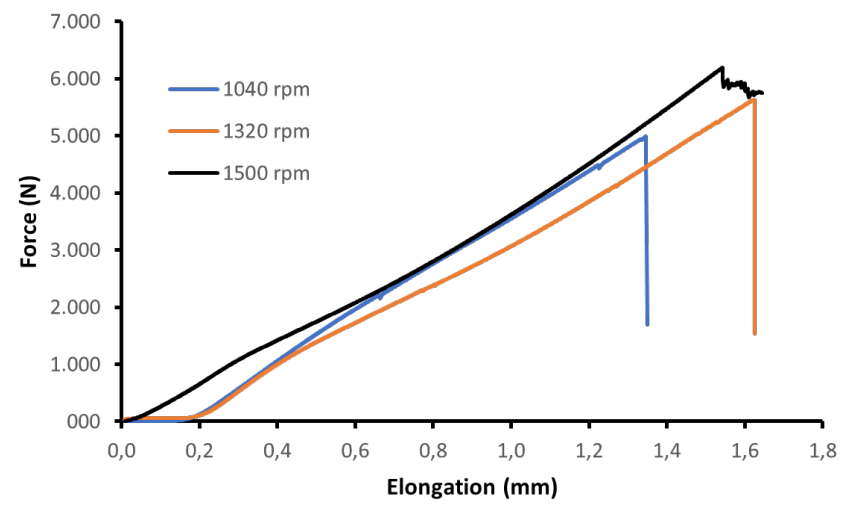

Fig. 8. Force-elongation curves obtained from the tensile test of FSS-welded plates using different rotation speeds (1040, 1320 and $1500 \mathrm{rpm})$

\subsection{Investigation of Hardness Values}

The relationship between the Vickers hardness values of the welded parts obtained by using different rotational speeds were presented in Figure 9. Microhardness tests were performed $0.2 \mathrm{~mm}$ above the joint interface. It was observed that the hardness values were higher in the base material and stir zone and the hardness values were lower in the TMAZ. Similar results were obtained for hardness values for different tool rotation speeds. However it was found that the hardness values of the sample joined with $1040 \mathrm{rpm} \mathrm{dec-}$ reased in the region closer to the welding center. This result shows that the sheets joined at $1040 \mathrm{rpm}$ have a smaller stir zone. Venukumar et al. [26] explained that the decrease in hardness value is caused by the formation of coarse grains as a result of over-aging. They explained the increase in hardness in the stir zone with high temperature and plastic deformation causing dynamic recrystallization and fine grain structure. Yuan et al. [27] have obtained similar results and stated that the decrease in hardness value occurred as a result of thermal cycling.

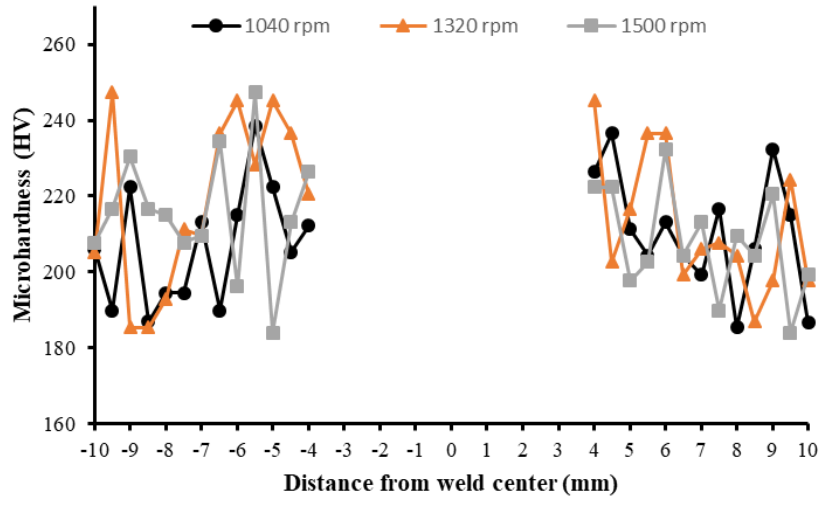

Fig. 9. Vickers hardness values of plates joined by FSS welding using different rotational speeds (1040, 1320 and $1500 \mathrm{rpm}$ )

\section{CONCLUSION}

In the metallographic examination of AA7075-T6 aluminum alloy sheets were joined by FSS welding under different welding conditions. A small amount of porosity was determined in the welding zone of the specimens produced at 1040 and $1320 \mathrm{rpm}$ tool rotation speeds. No welding defects including porosity were detected in the welding zone of the specimens produced at a tool rotation speed of $1500 \mathrm{rpm}$.

The study also demonstrated that the tool speed in the FSSW method has a significant effect on the tensile force of the joint.

\section{ACKNOWLEDGMENT}

We would like to thank Assoc. Prof. Dr. Hüseyin ŞEVIKK who assisted in the tensile testing of the specimens in this study.

\section{REFERENCES}

[1] Jedrasiak, P., Shercliff, H.R., Reilly, A., McShane, G.J., Chen, Y.C., Wang, L., Robson, J., Prangnell, P. (2016). Thermal modeling of al-al and al-steel friction stir spot welding. Journal of Materials Engineering and Performance, 25(9): 4089-4098, DOI: 10.1007/s11665-0162225-y.

[2] Rostamiyan, Y., Seidanloo, A., Sohrabpoor, H., Teimouri, R. (2015). Experimental studies on ultrasonically assisted friction stir spot welding of AA6061. Archives of Civil and Mechanical Engineering, 15(2): 335-346, DOI: 10.1016/j.acme.2014.06.005.

[3] Tutar, M., Aydin, H., Yuce, C., Yavuz, N., Bayram, A. (2014). The optimisation of process parameters for friction stir spot-welded AA3003-H12 aluminium alloy using a taguchi orthogonal array. Materials and Design, 63: 789-797, DOI: 10.1016/j.matdes.2014.07.003.

[4] Su, Z.M., He, R.Y., Lin, P.C., Dong, K. (2014). Fatigue analyses for swept friction stir spot welds in lap-shear specimens of alclad 2024T3 aluminum sheets. International Journal of Fatigue, 61: 129-140, DOI: 10.1016/j.ijfatigue.2013.11.021.

[5] Wang, D.A., Lee, S.C. (2007). Microstructures and failure mechanisms of friction stir spot welds of aluminum 6061-t6 sheets. Journal of Materials Processing Technology, 186(1-3): 291-297, DOI: 10.1016/j. jmatprotec.2006.12.045.

[6] Cakan, A., Atmaca, H., Ugurlu, M. (2018). Analysis and joining of al-cu plates using friction-stir welding technique. European Mechanical Science, 2(1): 1-8, DOI: 10.26701/ems.358729.

[7] Yazdipour, A., Heidarzadeh, A. (2016). Effect of friction stir welding 
on microstructure and mechanical properties of dissimilar Al 5083H321 and 316L stainless steel alloy joints. Journal of Alloys and Compounds, 680: 595-603, DOI: 10.1016/j.jallcom.2016.03.307.

[8] Sinha, V.C., Kundu, S., Chatterjee, S. (2016). Microstructure and mechanical properties of similar and dissimilar joints of aluminium alloy and pure copper by friction stir welding. Perspectives in Science, 8: 543-546, DOI: 10.1016/j.pisc.2016.06.015.

[9] Cam, G., Serindag, H.T., Cakan, A., Mistikoglu, S., Yavuz, H. (2008). The effect of weld parameters on friction stir welding of brass plates. Materialwissenschaft und Werkstofftechnic, 39(6): 394-399, DOl: 10.1002/mawe.200800314.

[10] Cam, G., Gucluer, S., Cakan, A., Serindag, H.T. (2009). Mechanical properties of friction stir butt-welded Al-5086 H32 plate. Materialwissenschaft und Werkstofftechnic, 40(8): 638-642, DOI: 10.1002/ mawe.200800455.

[11] Uzun, H., Donne, C.D., Argagnotto, A., Ghidini, T., Gambaro, C. (2005). Friction stir welding of dissimilar Al 6013-T4 to X5CrNi18-10 stainless steel. Materials and Design, 26(1): 41-46, DOI: 10.1016/j. matdes.2004.04.002.

[12] Shen, Z., Yang, X., Zhang, Z., Cui, L., Li, T. (2013). Microstructure and failure mechanisms of refill friction stir spot welded 7075-T6 aluminum alloy joints. Materials and Design, 44: 476-486, DOI: 10.1016/j. matdes.2012.08.026.

[13] Zhang, Z., Yang, X., Zhang, J., Zhou, G., Xu, X., Zou, B. (2011). Effect of welding parameters on microstructure and mechanical properties of friction stir spot welded 5052 aluminum alloy. Materials and Design, 32(8-9): 4461-4470, DOI: 10.1016/j.matdes.2011.03.058.

[14] Shen, J., Min, D., Wang, D. (2011). Effects of heating process on the microstructures and tensile properties of friction stir spot welded AZ31 magnesium alloy plates. Materials and Design, 32(10): 50335037, DOI: 10.1016/j.matdes.2011.05.046.

[15] Tozakia, Y., Uematsub, Y., Tokaji, K. (2010). A newly developed tool without probe for friction stir spot welding and its performance. Journal of Materials Processing Technology, 210(6-7): 844-851, DOI: 10.1016/j.jmatprotec.2010.01.015.

[16] Luo, T., Shı, B., Duan, Q., Fu, J., Yang, Y. (2013). Fatigue behavior of friction stir spot welded AZ31 Mg alloy sheet joints. Transactions of Nonferrous Metals Society of China, 23(7): 1949-1956, DOI: 10.1016/S1003-6326(13)62682-5.

[17] Sun, Y., Fujii, H., Zhua, S., Guan, S. (2019). Flat friction stir spot welding of three 6061-T6 aluminum sheets. Journal of Materials Processing Technology, 264: 414-421, DOI: 10.1016/j.jmatprotec.2018.09.031.

[18] Babu, S., Sankar, V., Ram, G.J., Venkitakrishnan, P., Reddy, G.M., Rao, K.P. (2013). Microstructures and mechanical properties of friction stir spot welded aluminum alloy AA2014. Journal of Materials Engineering and Performance, 22(1): 71-84, DOI: 10.1007/s11665-0120218-z.

[19] Merzoug, M., Mazari, M., Berrahal, L., Imad, A. (2010). Parametric studies of the process of friction spot stir welding of aluminium 6060-T5 alloys. Materials and Design, 31(6): 3023-3028, DOl: 10.1016/j.matdes.2009.12.029.

[20] Cao, X., Jahazi, M. (2011). Effect of tool rotational speed and probe length on lap joint quality of a friction stir welded magnesium alloy. Materials and Design, 32(2011): 1-11, DOl: 10.1016/j-matdes.2010.06.048.

[21] Zhang, Z., Yang, X., Zhang, J., Zhou, G., Xu, X., Zou, B. (2011). Effect of welding parameters on microstructure and mechanical properties of friction stir spot welded 5052 aluminium alloy. Material and Design, 32(2011): 4461-4470, DOI: 10.1016/j.matdes.2011.03.058.
[22] Gerlich, A., Su, P., Yamamoto, M., North, T. H. (2007), Effect of welding parameters on the strain rate and microstructure of friction stir spot welded 2024 aluminum alloy. Journal of Materials Science, 42: 5589-5601, DOI: 10.1007/s10853-006-1103-7.

[23] Bozzi, S., Helbert-Etter, A. L., Baudin, T., Klosek, V., Kerbiguet, J. G., Criqui, B. (2010). Influence of FSSW parameters on fracture mechanisms of 5182 aluminium welds. Journal of Materials Processing Technology, 210(11): 1429-1435, DOI: 10.1016/j.jmatprotec.2010.03.022

[24] Paidar, M., Khodabandeh, A., Najafi, H., Rouh-aghdam, A. S. (2014). Effects of the tool rotational speed and shoulder penetration depth on mechanical properties and failure modes of friction stir spot welds of aluminum 2024-T3 sheets. Journal of Mechanical Science and Technology, 28(12): 4893-4898. DOI: 10.1007/s12206-014-11080 .

[25] Patel, V. V., Sejani, D. J., Patel, N. J., Vora, J. J., Gadhvi, B. J., Padodara, N. R., Vamja, C. D. (2016). Effect of tool rotation speed on friction stir spot welded AA5052-H32 and AA6082-T6 dissimilar aluminum alloys. Metallography, Microstructure, and Analysis, 5(2): 142-148, DOI: 10.1007/s13632-016-0264-2.

[26] Venukumar, S., Yalagi, S., Muthukumaran S. (2013). Comparison of microstructure and mechanical properties of conventional and refilled friction stir spot welds in AA 6061-T6 using filler plate. Transactions of Nonferrous Metals Society of China, 23(2013): 2833-2842, DOI: 10.1016/S1003-6326(13)62804-6.

[27] Yuan, W., Mishra, R. S., Webb, S., Chen, Y. L., Carlson, B., Herling, D. R., Grant, G. J. (2010). Effect of tool design and process parameters on properties of Al alloy 6016 friction stir spot welds. Journal of Materials Processing Technology, 211(2011): 972-977, DOl: 10.1016/j. jmatprotec.2010.12.014. 